\title{
Comparison of the Effect of Muscle Relaxation and Guided Imagery on Happiness and Fear of Childbirth in Primiparous Women Admitted to Health Care Centers
}

\author{
Tahereh Boryri $^{{ }^{+}(\mathbb{D}}$, Ali Navidian ${ }^{2}$, Nasimeh Marghzari $^{3}$
}

\begin{abstract}
Objectives: Giving birth is a unique experience that requires a pregnant woman's ability to cope with labor pain. Using happiness, this potential can be given to a pregnant woman. This study was performed to compare the effect of muscle relaxation and guided imagery on the happiness and fear of delivery in primiparous women.

Materials and Methods: This quasi-experimental study was carried out on a sample of 180 primiparous women who referred to healthcare centers in Zahedan during 2017. The subjects were selected by the available sampling method. Then, Brislin's and Oxford Questionnaires were used to evaluate the fear of childbirth (FOC) and happiness, respectively. Through simple randomization, people who were qualified were included in relaxation, guided imagery, and control groups. Finally, a four-week training program was implemented for individual training.

Results: Before the intervention, the mean scores for the FOC in relaxation, guided imagery, and control groups were $39.51 \pm$ $6.91,44.00 \pm 9.30$, and $41.56 \pm 9.37$, respectively, and after the intervention, they were $30.45 \pm 6.56,34.78 \pm 9.36$ and $41.78 \pm 8.69$, respectively. Based on the results, the mean scores of the FOC after the intervention showed a significant difference among the groups $(P=0.0001)$. In addition, the mean scores for happiness were $37.5 \pm 15.54,34.54 \pm 17.72$, and $36.78 \pm 18.97$, as well as $54.66 \pm$ $14,49.63 \pm 17.05$, and $36.65 \pm 18.28$ before and after the intervention in relaxation, guided imagery, and control groups, respectively $(P=0.0001)$.

Conclusions: To prevent unnecessary cesarean sections, the current study confirmed the effect of muscle relaxation and guided imagery techniques for reducing the fear of delivery while increasing happiness in pregnant women.

Keywords: Happiness, Fear of Childbirth, Muscle Relaxation, Guided Imagery, Primiparous
\end{abstract}

\section{Introduction}

For each woman, pregnancy, childbirth, and maternity are considered as social and emotional processes that are accompanied by important consequences (1). The fear of giving birth involves a spectrum of extreme to a rational fear of delivery. Most women, especially those who are nulliparous, experience a logical fear because of their unfamiliarity with the labor process. Naturally, this fear can be controlled during pregnancy and delivery (2). Based on the reports, the fear of giving birth is the reason for 7\%-22\% of cesareans in Finland, Sweden, and the United Kingdom (3). Additionally, according to the studies conducted in Iran, the fear of vaginal delivery is reported as the reason for $59 \%$ of cesareans (4). However, there are many reasons for the fear of having a vaginal birth, including the fear of pain, death and unexpected problems, the low self-efficacy of childbirth, concerns about postpartum sexual problems, and baby health concerns are among the main causes of the fear of childbirth (FOC) (3).

Happiness is a fundamental criterion of mental health which includes anger, fear, disgust, surprise, and sadness (5).

Some studies demonstrated that there is an increase in the happiness level during pregnancy, which is associated with self-actualization and the consolidation of gender identity in pregnancy $(6,7)$. Hagstrom et al, investigating the factors related to happiness in pregnancy, showed that $57 \%$ of mothers had a high level of happiness and the remaining mothers reported a moderate level of happiness while none of them expressed a low level of happiness during pregnancy (6).

Sable and Libbus discovered that approximately half of the mothers were very happy about their pregnancies despite unwanted pregnancies (7).

Although guided imagery is used for relaxation in pregnant women, muscle relaxation technique is a systematic method for adjusting stress and promoting deep relaxation and happiness in pregnant women. This technique can be effectively carried out to adjust the stress, relieve anxiety, and reduce the symptoms or signs of stress. In addition, this technique provides a complete relaxation

Received 5 March 2018, Accepted 30 July 2018, Available online 27 November 2018

${ }^{1}$ Department of Midwifery, Pregnancy Health Research Center, Zahedan University of Medical Sciences, Zahedan, Iran. ${ }^{2}$ Department of Counseling, Pregnancy Health Research Center, Zahedan University of Medical Sciences Zahedan, Iran. ${ }^{3}$ Department of Midwifery, Zahedan University of Medical Sciences Zahedan, Iran.

*Corresponding Author: Tahereh Boryri, Email:boryri_tahereh@yahoo.com 
by the regular practice and can lead to both meaningful changes in physiological stress and muscle conditions to a better approach (8).

Likewise, guided imagery is a sort of relaxation by which one deliberately builds one's bloodstream and enhances the capacity of the bloodstream in the organs by practicing withdrawal developments and discharging them to a free and extending state inside 5-10 seconds. Utilizing this strategy, the muscles are isolated into eight sections such as the privilege and left leg, the stomach, the midsection, the hips, the chest and back, the privilege and left hand, the neck, as well as the head and face muscles.

How to use this technique is so clear in a way that the pieces of advice can be recorded on a tape and given to the pregnant women to practice at home $(9,10)$. Muscle relaxation can improve the outcomes of pregnancy resulting in a positive effect on the mental state of pregnant women. The outcomes of employing this technique include reducing the complications related to health problems during pregnancy, prolonging the gestational age, decreasing the rates of cesarean section, and decreasing postpartum problems $(11,12)$.

In general, there are no serious side effects on using this method although complications such as palpitations, muscle cramps, increased blood pressure, and anxiety may be found in some cases (13).

Utilizing the guided imagery technique, primiparous ladies are encouraged to take a profound abdominal or diaphragmatic breathing in order to relax their muscles, envision the view (e.g., backwoods, seashore, and zone in the journey), and center around encompass sounds and scents for 20 minutes. Further, muscle relaxation and guided imagery are frequently utilized together on the grounds that guided imagery can improve the procedure of muscle relaxation and prompt an expansion in its impact (14).

Considering the high predominance of labor fear in the study population (primiparous ladies), happiness and fertility can be assumed an imperative part in decreasing apparent agony and enhancing personal satisfaction during pregnancy.

The oddity of the present examination is to find the best technique for reducing pregnant women's fears while increasing their happiness. Accordingly, this investigation intended to assess the levels of satisfaction in pregnant ladies who were prepared by two methods of muscle relaxation and guided imagery contrasted with controls among primiparous ladies who were admitted to Zahedan health care centers in Sistan and Baluchistan province of Iran.

\section{Materials and Methods}

The population of this quasi-experimental research consisted of 180 primiparous women who referred to healthcare centers for prenatal care in 2017. The subjects were selected by the available sampling method. The inclusion criteria were being within the age range of 18-35 years and the gestational age of 26-32 weeks, having no medical and surgical complications, as well as experiencing monocularity and wanted pregnancy. Moreover, their past medical and social histories included no history of mental or physical chronic diseases, substance abuse, major stressful life events during the past six months, and training for vaginal delivery. The subjects were divided into three groups of control, muscle relaxation, and guided imagery by simple randomization and then, the pretest was applied to them. Routine care was only provided for patients in the control group. The pregnant women in both groups of relaxation and guided imagery individually received two 90-minute training sessions for four weeks in the health care center. Further, pregnant women in both the above-mentioned groups were given practical training by using training CDs. They repeated the exercises 30 minutes a day at home and filled out the checklist. After the 4-week training, they were asked to participate in the post test. Demographic information form, delivery fear questionnaire, and the Oxford Happiness Questionnaire were used for collecting data. Brislin's questionnaire was employed to assess the FOC. The principles mentioned by Brislin et al (15) were used to obtain a questionnaire equivalent to the destination language. First, two linguists independently translated the questionnaires into Persian. Then, the other two linguists translated the Persian version independently into English, and after finalizing, the version provided by the bilingual specialist was compared with the original version. Next, the final version was verified by a panel of experts to determine the content validity and very few changes were made accordingly. The original questionnaire included 16 items. According to the experts' panel, two items were deleted and a 14-item questionnaire was used for the aim of the study. The responses to the questions were in the form of a 4-point Likert-type scale (including at all, low, moderate, and high) and scores 1-4 were considered for each question with respect to the 4-point Likert-type scale. Thus, scores ranged from 14 to 56 and higher levels of fear showed higher scores. As there was no cutting score for the fear of delivery, similar oversee research was reviewed to determine the cutoffs. Everyone who had a score of 28 or higher was considered as a person with the fear of delivery. Cronbach $\alpha$ as a measure was used to evaluate the internal consistency and the reliability of the delivery fear questionnaire was calculated to be 0.81 . Furthermore, the Oxford Happiness Questionnaire included 29 items with a six-point Likert-type scale (ranging from totally agree to totally disagree) that was completed by the participants. The scores ranged from 29 to 174 and contained three levels of low (less than or equal to 100), moderate (101131 ), and high (more than or equal to 132) happiness (6). Hadinejad and Zareei verified the validity of the Persian translation of this questionnaire. Face and content validity was verified by a number of experts in 2009 as well. 
Moreover, Hadinejad and Zareei checked the reliability of this instrument through re-testing with a 4-week interval and a correlation coefficient of $78 \%$ at a significance level of 0.001 (16.17). In this study, its reliability was calculated by Cronbach $a(r=0.73)$. Pirdadeh Beiranvand et al (18) reported the FOC of $80.8 \%$ for pregnant women. According to the fear rate of Pirdadeh Beiranvand et al study and considering 0.05 errors for the $95 \%$ confidence interval, the sample size of 180 including 60 subjects in each group were considered for this study. The one-way analysis of variance (ANOVA) was employed to compare the mean and standard deviation of the happiness scores in the three groups. Eventually, the paired $t$ test was used to compare the groups before and after the intervention.

\section{Results}

The mean age and the mean of the gestational age of the participants were $24.54 \pm 4.40$ and $28.64 \pm 0.85$, respectively. There were no statistically significant differences among the three groups with respect to maternal age, gestational age, occupation and the infant's gender $(P>0.05)$. However, a significant difference was observed among the three groups regarding the level of education $(P=0.005)$. Table 1 summarizes the demographic and midwifery characteristics of the study participants.

Based on the results of the ANOVA test, the mean scores of satisfaction were not altogether extraordinary among the three groups before the mediation $(P=0.63)$ although the distinction was statistically significant $(P=0.0001)$ after the intervention. The post-hoc test demonstrated that there was no significant difference between the relaxation and guided imagery groups with respect to the average happiness $(P=0.01)$. Nevertheless, the results of both relaxation and control groups $(P=0.0001)$, as well as guided imagery and control groups $(P=0.0001)$ were statistically significant (Table 2).

The results of Table 3 showed that the scores of delivery fear before the intervention significantly differed in the three groups $(P=0.01)$. Based on the results of Tukey's post-hoc test, a significant difference was found between relaxation and guided imagery groups $(P=0.01)$ while the other groups represented no difference. However, the mean score of the fear of delivery was significant in the three groups after the intervention $(P=0.0001)$. The post-hoc test further indicated a statistically significant difference in the mean scores of childbirth fear between the relaxation and guided imagery groups $(P=0.0001)$, relaxation and control groups $(P=0.0001)$, as well as guided imagery and control groups $(P=0.0001)$, the details of which are provided in Table 3.

\section{Discussion}

The present study was performed to assess the comparative effects of muscle relaxation and guided imagery on happiness and the FOC in the primiparous women admitted to Zahedan health care centers in 2017. The findings demonstrated that both muscle relaxation and guided imagery could increase happiness and decrease the FOC in nulliparous women.

Pregnancy is associated with many physical and psychological changes that are more critical in primiparous women (19). The findings of a study conducted by Rahimi et al revealed the effectiveness of muscle relaxation in reducing anxiety and the fear of delivery in the women of the intervention group (20). According to Manzoni et al, the effect of training improved when the exercises were carried out for a longer period of time at home (21). This is consistent with the results of our study in which the intervention lasted for four sessions at home. On the other hand, relaxation sessions were helpful in reducing anxiety and depression while physical exercises reduced the energy level leading to more fatigue for pregnant women. Our results also revealed that both training relaxation and guided imagery decreased the fear of delivery while they increased happiness in pregnant women.

However, the score of training relaxation has ever been

Table 1. Comparison of Demographic and Midwifery Characteristics in 3 Groups of Participants

\begin{tabular}{|c|c|c|c|c|c|}
\hline \multirow{2}{*}{ Variables } & & \multicolumn{3}{|c|}{ Groups } & \multirow[b]{2}{*}{$P$ Value } \\
\hline & & Muscle Relaxation & Guided Imagery & Control & \\
\hline Mother's age (mean \pm SD) & & $26.63 \pm 4.76$ & $23.73 \pm 4.39$ & $23.27 \pm 4.19$ & $0.83^{\mathrm{a}}$ \\
\hline Gestational age (mean \pm SD) & & $28.85 \pm 0.79$ & $28.82 \pm 0.93$ & $28.25 \pm 0.83$ & $0.67^{a}$ \\
\hline \multirow{3}{*}{ Education level } & Above diploma & $22(36.7 \%)$ & $14(23.3 \%)$ & $8(13.3 \%)$ & \multirow{3}{*}{$0.005^{\mathrm{a}}$} \\
\hline & Diploma & $19(31.7 \%)$ & $28(46.7 \%)$ & $21(35 \%)$ & \\
\hline & Below diploma & $17(28.3 \%)$ & $15(25 \%)$ & 31 (51.7\%) & \\
\hline \multirow{2}{*}{ Occupation } & Employed & $7(18.3 \%)$ & $9(15 \%)$ & $4(6.7 \%)$ & \multirow{2}{*}{$0.15^{\mathrm{a}}$} \\
\hline & Unemployed & $49(81.7 \%)$ & $51(85 \%)$ & $56(93.3 \%)$ & \\
\hline \multirow{2}{*}{ Infant's gender } & Boy & $38(63.3 \%)$ & $36(60 \%)$ & $41(68.3 \%)$ & \multirow{2}{*}{$0.63^{a}$} \\
\hline & Girl & $22(36.7 \%)$ & $24(40 \%)$ & $19(31.7 \%)$ & \\
\hline Total number of subjects & & & 180 & & \\
\hline
\end{tabular}

SD, standard deviation.

a One-way analysis of variance (ANOVA). 
Table 2. Score Comparison Before and After the Intervention Regarding Happiness in 3 Groups of Participants

\begin{tabular}{|c|c|c|c|}
\hline \multirow{3}{*}{ Group } & \multicolumn{2}{|c|}{ Time } & \multirow{3}{*}{$P$ Value $^{\mathrm{a}}$} \\
\hline & Before intervention & After intervention & \\
\hline & Mean \pm SD & Mean \pm SD & \\
\hline Relaxation & $37.50 \pm 15.54$ & $54.66 \pm 14.26$ & 0.0001 \\
\hline Guided imagery & $34.54 \pm 17.72$ & $49.63 \pm 17.05$ & 0.0001 \\
\hline Control & $36.78 \pm 18.97$ & $236.65 \pm 18.28$ & 0.54 \\
\hline$P$ value ${ }^{b}$ & 0.63 & 0.0001 & \\
\hline
\end{tabular}

$\mathrm{SD}$, standard deviation.

a Paired $t$ test; ${ }^{\text {b ANOVA test. }}$

Table 3. Fear of Delivery Comparison Before and After Intervention in 3 Groups of Participants

\begin{tabular}{|c|c|c|c|}
\hline \multirow{3}{*}{ Group } & \multicolumn{2}{|c|}{ Time } & \multirow{3}{*}{$P$ Value $^{\mathrm{a}}$} \\
\hline & Before intervention & After intervention & \\
\hline & Mean \pm SD & Mean $\pm S D$ & \\
\hline Relaxation & $39.5 \pm 6.91$ & $30.45 \pm 6.56$ & 0.0001 \\
\hline Guided imagery & $44.00 \pm 9.30$ & $34.78 \pm 9.36$ & 0.0001 \\
\hline Control & $41.56 \pm 9.37$ & $41.78 \pm 8.69$ & 0.28 \\
\hline$P$ value ${ }^{\mathrm{b}}$ & 0.01 & 0.0001 & \\
\hline
\end{tabular}

$\mathrm{SD}$, standard deviation.

a Paired $t$ test; ${ }^{\mathrm{b}}$ ANOVA test.

higher than that of the guided imagery in reducing the fear of giving birth and increasing the level of happiness (22). Moreover, Khorsandi et al evaluated the effect of relaxation on reducing the fear and preferring a vaginal delivery in primiparous women and found that primiparous women who underwent relaxation training had lower fear scores compared to the control groups (23), which is in line with our findings. Contrarily, Tragea et al studied 31 nulliparous women in their second trimester of pregnancy. In their study, the intervention group received stress management exercises including deep breathing and muscle relaxation for 6 weeks although no statistically significant difference was observed in anxiety and the fear of delivery before and after the intervention. This is inconsistent with our results and some other studies which could be due to the limited number of participants in the Tragea et al study (24). In addition, Johnson and Slade reported no difference in the fear of delivery between women who had a vaginal delivery and those who had an emergency or elective cesarean section (25), which contradicts the results of our research, implying the effect of delivery fear in different cultures. The fear of giving birth is one of the influential factors at the end of pregnancy and triggers increased elective or emergency cesarean section. Therefore, more effort to reduce such fear in primiparous women is essential in prenatal care. The higher level of happiness is not unexpected due to the emotional support during pregnancy. This implies that although pregnancy is a critical and stressful condition in the life cycle of women with many physical, moral, and social changes, the sense of self-actualization, consolidation of women's identity, and the ability of childbearing and creativity lead to the increased sense of happiness in healthy women (26). The results of our study also revealed that both relaxation training and guided imagery techniques led to increased happiness in pregnant women, which corroborates with the findings of the study by Golmakani et al which investigated the relationship between happiness and the coping behaviors of labor pain (27). Further, Dezutter et al in their research evaluated the effect of trust in God and happiness on chronic pains and concluded that both the belief in God and happiness contributed to the chronic disease improvement (28).

Moreover, in line with our findings, Koopmans et al examined the impact of happiness on the mortality rate over 15 years and found that happiness was associated with less mortality and morbidity, especially when combined with physical activity (29). In addition, several studies confirmed lower levels of stress among happy individuals, but higher levels of stress among anxious and depressed people. Theoretically, happiness with physiological mechanisms can reduce stress, fear, fatigue, and pain during labor and thus provide more beneficial coping behaviors for the mother.

\section{Conclusions}

Considering the outcomes of this examination, preparation with muscle relaxation and guided imagery enhanced satisfaction and decreased the dread of conveyance in pregnant women. Likewise, the outcomes demonstrated that the measure of decline in fear because of labor was substantially higher in muscle relaxation 
compared to guided imagery. Keeping in mind the end goal of providing emotional well-being for pregnant ladies and stay away from superfluous cesareans, it is prescribed to make directing centers notwithstanding pre-birth to watch over pregnant ladies.

\section{Conflict of Interests}

Authors declare that they have no conflict of interests.

\section{Ethical Issues}

This paper, the result of a student thesis, was approved by the Ethics Committee of Zahedan University of Medical Sciences under the ethical code of IR. ZAUMS.RES1396098 and clinical trial code of IRCT20171230038133N1.

\section{Financial Support}

This study is the result of a MS thesis and was supported by Nursing and Midwifery, Zahedan University of Medical Sciences and Health Services, Zahedan, Iran.

\section{Acknowledgments}

The researcher and his colleagues would like to acknowledge the Research Deputy of Zahedan University of Medical Sciences, as well as all pregnant women who helped the author with lots of love and affection at all stages of the research.

\section{References}

1. Salmela-Aro K, Read S, Rouhe H, et al. Promoting positive motherhood among nulliparous pregnant women with an intense fear of childbirth: RCT intervention.J Health Psychol. 2012;17(4):520-534. doi:10.1177/1359105311421050

2. Salomonsson B, Wijma K, Alehagen S. Swedish midwives' perceptions of fear of childbirth. Midwifery. 2010;26(3):327337. doi:10.1016/j.midw.2008.07.003

3. Sydsjö G, Sydsjö A, Gunnervik C, Bladh M, Josefsson A. Obstetric outcome for women who received individualized treatment for fear of childbirth during pregnancy. Acta Obstet Gynecol Scand. 2012;91(1):44-49. doi:10.1111/ j.1600-0412.2011.01242.x

4. Zafarghandi N, Zafarghandi ASH, Hadavand SH, Zayeri F, Hamzeloo L. Risk factors associated with forth-degree laceration during vaginal delivery. Tehran University Medical Journal. 2006;64(7):65-74.

5. Jafari E, Liaghatdar M, Abedi M. Happiness and its degree of effective factors in students of the Isfahan Medical Sciences University. Teb va Tazkieh. 2004; 54:15-23.

6. Hagstrom PA, Wu S. Are pregnant women happier? Racial differences in the relationship between pregnancy and life satisfaction. Munich Personal RePEc Archive (MPRA); 2010. http://mpra.ub.uni-muenchen.de/24853.

7. Sable MR, Libbus MK. Pregnancy intention and pregnancy happiness: Are they different? Matern Child Health J. 2000;4(3):191-196. doi:10.1023/a:1009527631043

8. Patel MP. A study to assess the effectiveness of progressive muscle relaxation therapy on stress among staff nurses working in selected hospitals at Vadodara City. IOSR
Journal of Nursing and Health Science. 2014;3(3):34-59.

9. Domar AD, Eyvazzadeh A, Allen S, et al. Relaxation techniques for reducing pain and anxiety during screening mammography. AJR Am J Roentgenol. 2005;184(2):445447. doi:10.2214/ajr.184.2.01840445

10. Kordi M, Nasiri S, Modares Gharavi M, Ebrahimzadeh S. Evaluating the effect of progressive muscle relaxation training with guided imagery on the severity of depressive symptoms in postpartum period. The Iranian Journal of Obstetrics, Gynecology and Infertility. 2012;15(8):17-24. doi:10.22038/ijogi.2012.5712

11. Consonni EB, Calderon IM, Consonni M, De Conti MH, Prevedel T, Rudge MV. A multidisciplinary program of preparation for childbirth and motherhood: maternal anxiety and perinatal outcomes. Reprod Health. 2010;7:28. doi:10.1186/1742-4755-7-28

12. Fink NS, Urech C, Cavelti M, Alder J. Relaxation during pregnancy: what are the benefits for mother, fetus, and the newborn? A systematic review of the literature. J Perinat Neonatal Nurs. 2012;26(4):296-306. doi:10.1097/ JPN.0b013e31823f565b

13. Akmeşe ZB, Oran NT. Effects of Progressive Muscle Relaxation Exercises Accompanied by Music on Low Back Pain and Quality of Life During Pregnancy. J Midwifery Womens Health. 2014;59(5):503-509. doi:10.1111/ jmwh.12176

14. Achterberg J. Mind and medicine: The role of imagery in healing. J Am Soc Psych Res. 1989;83(2):93-100.

15. Brislin RW, Lonner WJ, Throndike RM. Cross-Cultural Research Methods. New York: John Wiley \& Sons; 1973. p. 32-58.

16. Hadinejad H, Zareei F. Reliability, validity, and normalization of the Oxford Happiness Questionnaire. Psychol Res. 2009;12(1-2):62-77. [Persian].

17. Sangrungnapaphan P. Husband Participation During Labor on Anxiety and Coping Behavior of Prim gravidas at Srinagarind Hospital Khon Kaen Province.[Thesis]. Thailand: Mahidol University; 1988.

18. Pirdadeh Beiranvand S, Behboodi Moghadam Z, Salsali M, Alavi Majd H, Birjandi M, Bostani Khalesi Z. Prevalence of Fear of Childbirth and Its Associated Factors in Primigravid Women: A Cross- Sectional Study. Shiraz E Med J. 2017;18(11):e61896. doi:10.5812/semj.61896

19. Shobeiri F, Taravati Javad M, Soltani J, Karami M. Effects of progressive muscle relaxation on preterm delivery among primigravida women referred to health care centers in Hamadan. The Iranian Journal of Obstetrics, Gynecology and Infertility. 2016;19(11):1-10. [Persian].

20. Rahimi F, Ahmadi M, Rosta F, Alavi Majd H, Valiani M. Effect of relaxation training on pregnancy anxiety in high risk women. Safety Promotion and Injury Prevention. 2015;2(3):180-188. [Persian].

21. Manzoni GM, Pagnini F, Castelnuovo G, Molinari E. Relaxation training for anxiety: a ten-years systematic review with meta-analysis. BMC Psychiatry. 2008;8:41. doi:10.1186/1471-244x-8-41

22. Striebich S, Mattern E, Ayerle GM. Support for pregnant women identified with fear of childbirth (FOC)/ tokophobia - A systematic review of approaches and interventions. Midwifery. 2018;61:97-115. doi:10.1016/j. 
midw.2018.02.013

23. Khorsandi M, Ghofranipour F, Heydarniya A, et al. The effect of childbirth preparation classes on childbirth fear and normal delivery among primiparous women. Arak Medical University Journal. 2008;11(3):29-36. [Persian].

24. Tragea C, Chrousos GP, Alexopoulos EC, Darviri C. A randomized controlled trial of the effects of a stress management programme during pregnancy. Complement Ther Med. 2014;22(2):203-211. doi:10.1016/j. ctim.2014.01.006

25. Johnson R, Slade P. Does fear of childbirth during pregnancy predict emergency caesarean section? BJOG. 2002;109(11):1213-1221.

26. Jannati Y, Khaki N. Psychiatry in Midwifery. Tehran:
Jameneghar Publisher; 2005. p. 144-145. [Persian].

27. Golmakani N, Hashemi Asl BM, Sajadi SA, Ebrahimzadeh S. The relationship between happiness during pregnancy, and labor pain coping behaviors. Evidence Based Care. 2012;2(2):85-93. doi:10.22038/ebcj.2012.403

28. Dezutter J, Luyckx K, Schaap-Jonker H, Büssing A, Corveleyn J, Hutsebaut D. God image and happiness in chronic pain patients: the mediating role of disease interpretation. Pain Med. 2010;11(5):765-773. doi:10.1111/ j.1526-4637.2010.00827.x

29. Koopmans TA, Geleijnse JM, Zitman FG, Giltay EJ. Effects of happiness on all-cause mortality during 15 years of follow-up: The Arnhem Elderly Study. J Happiness Stud. 2010;11(1):113-124. doi:10.1007/s10902-008-9127-0

(c) 2019 The Author (s); This is an open-access article distributed under the terms of the Creative Commons Attribution License (http://creativecommons.org/licenses/by/4.0), which permits unrestricted use, distribution, and reproduction in any medium, provided the original work is properly cited. 